Document downloaded from:

http://hdl.handle.net/10251/78696

This paper must be cited as:

Martí Albiñana, JV.; García-Segura, T.; Yepes, V. (2016). Structural design of precastprestressed concrete U-beam road bridges based on embodied energy. Journal of Cleaner Production. 120:231-240. doi:10.1016/j.jclepro.2016.02.024.

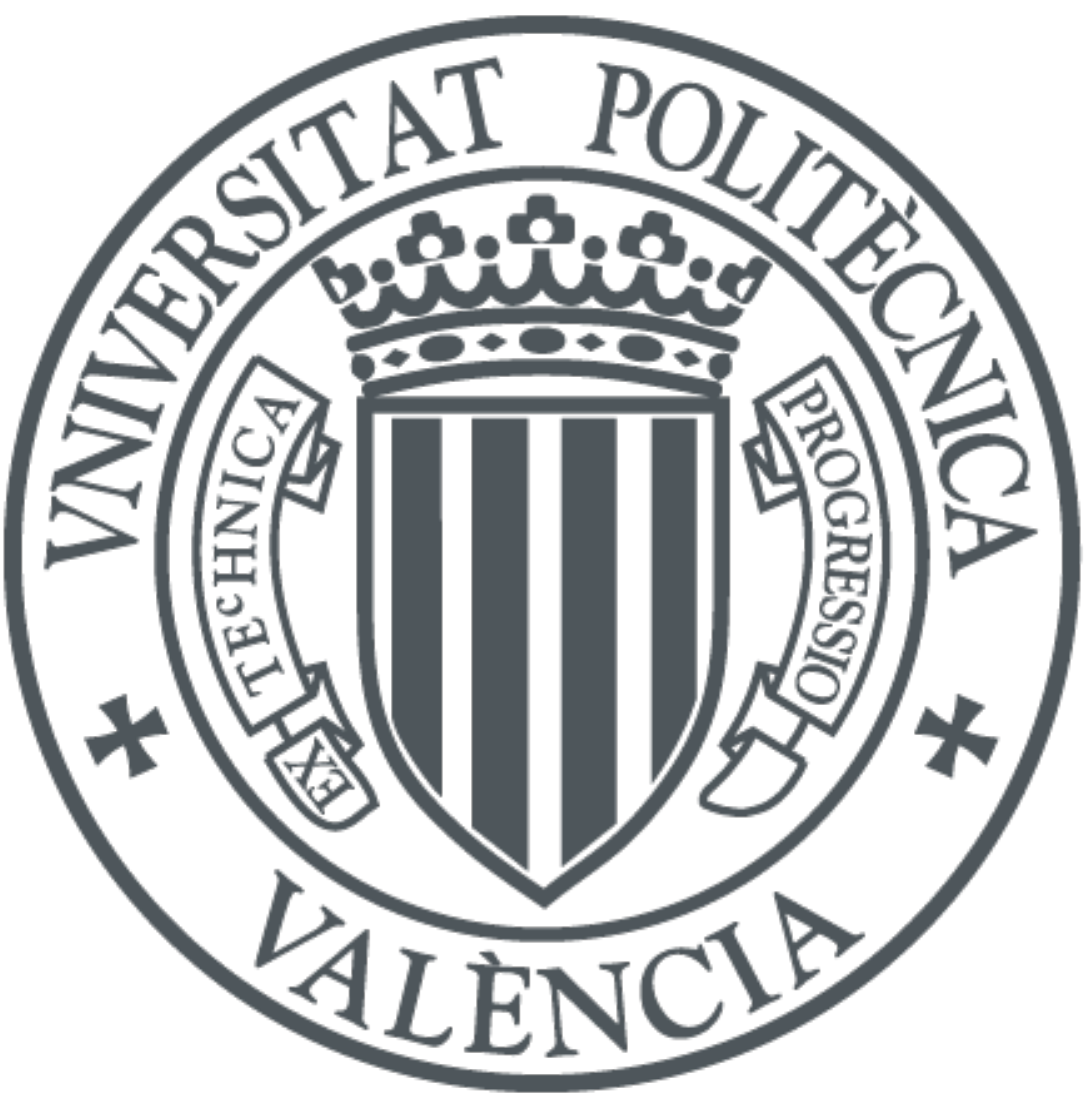

The final publication is available at

http://dx.doi.org/10.1016/j.jclepro.2016.02.024

Copyright Elsevier

Additional Information 


\title{
Structural design of precast-prestressed concrete U-beam road bridges based on embodied energy
}

\author{
José V. Martí1 \\ Tatiana García-Segura ${ }^{2}$ \\ Víctor Yepes ${ }^{3}$
}

\begin{abstract}
An automated procedure for optimizing the design of precast-prestressed concrete U-beam road bridges is presented. The economic cost and the embodied energy are selected as the objective functions based on production materials, transport and placement. Heuristic optimization is used to search for the best geometry, the concrete type, the prestressing steel, and the reinforcement for the slab and the beam. The results for both objectives provide improved opportunities to learn about low-energy designs. The most influential variables for the energy efficiency goal are analyzed. The relationship between the span length and the embodied energy is described by a good parabolic fit for both optimization criteria. The findings indicate that the objectives do not exhibit conflicting behavior, and also that optimum energy designs are close to the optimum cost designs. The analysis also revealed that a reduction by 1 Euro can save up to $4 \mathrm{kWh}$. It is recommended to reduce the reinforcement in the slab as well as increase the volume of concrete in both slab and beams in order to achieve higher energy efficiency. It is also worth noting that web inclination angle should be increased when the depth increases for longer span lengths to maintain the optimum slab span lengths in the transverse direction.
\end{abstract}

\section{Keywords}

Heuristic optimization; energy savings; sustainable construction; precast-prestressed concrete structures

\footnotetext{
${ }^{1}$ Associate Professor, Institute of Concrete Science and Technology (ICITECH), Universitat Politècnica de València, 46022 Valencia, Spain. E-mail: jvmartia@upv.es

${ }^{2}$ Graduate Research Assistant, Institute of Concrete Science and Technology (ICITECH), Universitat Politècnica de València, 46022 Valencia, Spain. E-mail: tagarse@cam.upv.es

${ }^{3}$ Associate Professor, Institute of Concrete Science and Technology (ICITECH), Universitat Politècnica de València, 46022 Valencia, Spain. Corresponding author. Phone -34963879563; Fax: +34963877569; E-mail: vyepesp@upv.es
} 


\section{Introduction}

The construction industry is one of the largest consumers of natural resources. This industry consumes over $40 \%$ of all raw stone, gravel, and sand, $25 \%$ of all raw timber, $40 \%$ of energy, and $16 \%$ of the water used annually in the world (Lippiatt, 1999). Concrete production exceeds 23 billion tons annually (World Business Council for Sustainable Development, 2009). Regarding the energy, other studies indicate that the cement industry consumes about 5\% of the total industrial energy consumption (World Energy Counc., 1995).

In recent year, researchers have explored new ways to progress towards a sustainable construction. Zhong and $\mathrm{Wu}$ (2005) provided a guidance to select structural materials based on economic sustainability, environmental sustainability and constructability performance indicators. More recently, Castañon et al. (2015) focused on the economic and environmental benefits of optimizing the production process of cement. Pellicer et al. (2016) proposed an active-learning method to motivate students to take infrastructural sustainability into consideration. Senaratne et al. (2016) presented the sustainable advantages of a new structural material, which combines the recycled aggregate and steel fibers. Likewise, Tosic et al. (2015) studied the optimal amount of recycled concrete aggregate to achieve the best sustainable solution and Marti et al. (2015) pointed out the economic feasibility of steel fibers in precast-prestressed concrete road bridges.

Reducing construction emissions has been the subject of intensive research. Börjesson and Gustavsson (2000) and González and García-Navarro (2006) have focused on comparing the emissions for different materials in construction activity. Other authors have concentrated on evaluating the life cycle greenhouse gas emissions of concrete structures (García-Segura et al., 2014a; Barandica et al., 2013; Tae et al., 2011). Similarly, the embodied energy of construction projects are estimated to measure the sustainability (Wang and Shen, 2013; Wang et al., 2012). Miller et al. (2015) stated that post-tensioned slabs consumed less embodied energy than reinforced concrete slabs. Likewise, they proved that embodied energy efficiencies lead to structural weight reductions. However, Foraboschi et al. (2014) declared that the lowest weight does not guarantee the lowest embodied energy.

Several recent studies have focused on considering the environmental aspects of construction as a criterion for optimization. Reinforced concrete structures, such as, columns (de Medeiros and Kripka, 2014; Park et al., 2013), beams (Yepes et al., 2015a; García-Segura et al., 2014b), walls (Yepes et al., 2012) and footings (Camp 
and Assadollahi, 2013), among others, have been optimized to reduce the $\mathrm{CO}_{2}$ emissions. Regarding prestressed concrete (PC), examples can be found, although to a lesser extent, in precast-PC U-beam road bridges (Yepes et al., 2015b) and post-tensioned concrete box-girder pedestrian bridges (García-Segura et al., 2015). The embodied energy has been selected as an interesting objective for structural optimization (Yeo and Gabbai, 2011; Miller et al., 2015; Quaglia et al., 2014; Sattary and Thorpe, 2012).

In this paper, an automated procedure to optimize the embodied energy by finding the best structural design is presented. The energy-optimized results are compared to cost-optimized solutions. The proposed approach is illustrated on precast-PC U-beam road bridges. However, this framework can be applied to any structural case. A hybrid simulated annealing algorithm solves this complex problem with a mutation operator.

\section{Problem definition}

\subsection{Optimization algorithm}

The present study aims to develop an automated procedure that produces optimal structural designs for cost and energy criteria. The discrete variables define the geometry, prestressing and reinforcing steel, and concrete grade of precast-PC road bridges with a double U-shaped cross-section. The economic cost and the embodied energy are selected as the objective functions taking into account material production, transport and placement. The constraints guarantee the compliance of all the serviceability limit states (SLSs) and ultimate limit states (ULSs). Besides, the constraints check the geometric and constructability requirements.

A hybrid simulated annealing (SA) algorithm with a mutation operator (SAMO2) is used to combine the advantages of good convergence of SA and the promotion of the diversity of the genetic strategy. SA, proposed by Kirkpatrick et al. (1983), is based on the analogy of crystal formation. Adjusting the temperature $(T)$ in turn modifies the probability of adopting worse solutions. Genetic algorithms (Holland 1975) seek the best solution through operators such as selection, crossover and mutation. Li and Wei (2008) and Soke and Bingul (2006) have combined effectively both algorithms. The probability of acceptance $p_{a}$ is evaluated according to the temperature and the increment in the objective function value with the new configuration $\Delta E$ (Eq. 1). This acceptance function can reject favorable solutions. Figure 1 shows the flowchart of the process.

$$
\mathrm{p}_{a}=\frac{1}{1+e^{\frac{\Delta E}{T}}}
$$


The algorithm was coded in Intel® Visual Fortran Compiler Integration for Microsoft Visual Studio 2008. The computer is an Intel® CoreTM i7-3820 CPU processor and 3.6 GHz. The computing time necessary to run the algorithm is about $70 \mathrm{~min}$. The algorithm calibration recommended an initial temperature equal to $0.3 \%$ of the initial objective value, Markov chains of 5000 iterations, a cooling coefficient of 0.85 , and mutation operator with a random variation of $5 \%$ of the variables. The algorithm finishes when the temperature is lower than $10 \%$ of the initial temperature and there are no acceptances in six consecutive Markov chains.

\subsection{Objective functions}

Sustainability is quantified in terms of embodied energy $(E)$ and economic cost $(C)$. The embodied energy is the one required to extract, process, manufacture, and transport the materials, as well as the placement. Likewise, the cost includes the materials (concrete, active prestressing steel, passive reinforcement steel) and other elements to assess the entire cost of the construction. Eq. (2) and Eq. (3) are used to evaluate the energy and the cost. The unit energy $e_{\mathrm{i}}$ and price $p_{i}$ associated with each construction unit are multiplied by the measurements $m_{i}$ obtained from the solution. The database BEDEC (2013) and a survey of Spanish contractors are used to obtain the embodied energy and unit prices given in Tables 1, 2 and 3. The energy associated to the concrete slab unit includes transport and placement. It is assumed that the steel is mainly made in an electric arc furnace, approximately $40 \%$ from recycled scrap steel.

$$
\begin{aligned}
& E=\sum_{i=1, r} e_{i} \times m_{i} \\
& C=\sum_{i=1, r} p_{i} \times m_{i}
\end{aligned}
$$

\subsection{Design variables and parameters}

The structural problem uses 41 variables. The geometry is defined by nine variables (see Figs. 2, 3). The common variables are the width of the soffit of the beam $\left(b_{1}\right)$, the beam depth $\left(h_{1}\right)$, the width and thickness of the beam top flanges $\left(b_{3}\right.$ and $\left.e_{3}\right)$, the thickness of the bottom flange $\left(e_{1}\right)$, the web thickness $\left(e_{2}\right)$ and the slab thickness $\left(e_{4}\right)$. However, this study also considers the spacing between the beams $\left(s_{v}\right)$ and the web inclination angle (angl) as design variables. Two variables are used to determine the concrete grade for the slab and the beam. Regarding the prestressing steel, the strand diameter is fixed as 0.6 inch and the number of strands is 
divided into four variables. The number of strands are divided according to their position or layer (see Fig. 3). Finally, 26 variables are needed to define the reinforcement for the beam and the top slab, which is set in terms of bar diameters, spacing and bar lengths. Table 4 summarizes the parameters fixed for this case study.

\subsection{Constraints}

This module checks all the limit states and the geometric requirements. First, the module for structural evaluation calculates the stress envelopes. The codes followed for the structural analysis and evaluation are IAP-98 (Fomento 1998) and EHE-08 (Fomento 2008). The live load involves a three axes load of $200 \mathrm{kN}$ each and a superimposed uniform load of $4.0 \mathrm{kN} / \mathrm{m}^{2}$. Regarding the dead load, a load of $2 \times 0.5 \mathrm{kN} / \mathrm{m}$ consisting of a concrete bridge barrier rails along the edge of the deck is considered.

As table 4 indicate, the esthetic, ground and specific road transportation considerations lead to limit the slenderness of the beam to a minimum of $L / 17$, where $L$ is the span length. An interval of one month is considered to connect the beams and the slab to take into account the construction sequences. The stress resultants and reactions are calculated using a stiffness matrix program from a 2-D mesh with 20 bar elements. The 21 sections of each beam are connected by three bar elements. Therefore, the model is composed by 103 bar elements and 84 nodes. More details of the structural model can be found in Martí et al. (2013).

The deflections and the stress envelopes due to the loads are checked following the SLSs and ULSs of flexure and shear based on the Spanish Code (Fomento 2008). The SLS for cracking verifies the crack width limitation recommended for durability conditions. Moreover, a service working life is guaranteed for the durability limit state. Concrete fatigue and steel fatigue are also considered. Temporary and time-dependent deflection are limited to $1 / 250$ of the free span length for the frequency combination and 1/1000 of the free span length for the quasi-permanent combination, respectively. ULS verification check whether the ultimate values are greater than the factored acting. Since variables define the reinforcement, instead of the usual design rule, the structural problem is solved by checking. The beam flexure verification implies that the acting resultant bending $\left(M_{d}\right)$ is within the ultimate iteration diagram $N_{u}-M_{u}$. Finally, the program also test both flexural and shear minimum amounts of reinforcement, as well as the minimum geometric requirement.

\section{Results for the parametric study}

The parametric study was carried out for five span lengths ranging from 20 to $40 \mathrm{~m}$. Figures 4 and 5 show a 
slight difference between the two objectives. This implies that the objectives do not exhibit conflicting behavior, but also optimum energy is close to the optimum cost. The cost of PC precast road bridges with a double Ushaped cross-section and isostatic spans are, according to the span length, $C=44.265 s^{2}+1034.6 s+12208$ (with a regression coefficient $\left.R^{2}=0.9995\right)$ for energy optimization and $C=48.958 s^{2}+671.05 s+17407\left(R^{2}=0.9994\right)$ for cost optimization. Note that these relationships are valid within the range of the studied parameters. Similarly, the energy required for the bridge construction is represented as $E=191.69 s^{2}+4333.2 s+59141\left(R^{2}=0.9996\right)$ for energy optimization and $E=233.99 s^{2}+2198.1 s+99293\left(R^{2}=0.9964\right)$ for cost optimization. The findings indicate that energy consumption is related to the cost, as long as the reduction in material consumption reduces the associated cost and energy. When cost versus energy is represented (see Fig. 6), a $1 €$ reduction implies a $4 \mathrm{kWh}$ saving. Comparing the cost per square meter of deck, the energy optimization implies an average cost increment of $3.23 €$ per square meter of deck.

Cost and energy optimization lead to different structural solutions. Table 5 summarizes the mean values of the variables for both objectives. Design variables are analyzed to draw practical conclusions regarding low-energy designs. Figure 7 illustrates the mean optimum beam depth according to the span length. An average depth of the beam in relation to the span length is $1 / 18.15$ and $1 / 17.51 \mathrm{~m}$ in the cases of reducing cost and energy, respectively. While Fomento (2000) recommends a ratio $h 1 / L$ of $1 / 16$ for this bridge design, the optimization results show smaller depths. In consequence, the weight and the reinforcement required can be reduced.

The web inclination angle is commonly fixed as a parameter, regardless of the span length. However, Figure 8 shows the appropriateness of increasing the angle with the span length. For a 20-m span-length deck, an angle of around $62.5^{\circ}$ is the optimum solution. In the case where the span length is $40 \mathrm{~m}$, the cost-optimized solution and the energy-optimized solution have angles of $74^{\circ}$ and $75^{\circ}$, respectively. The explanation lies in the fact that the transverse bending influences over the election of this variable. With increasing span length, the depth also increases. Consequently, the angle should be increased to maintain the slab span length in the transverse direction, which prevents an unbalanced transverse bending in the slab.

Increasing the span length by $1 \mathrm{~m}$ increases the number of strands by 1.4 , whether for the cost or the energy objective (see Fig. 9). Thus, the number of strands is not a significant variable in reducing energy consumption. With regard to the mean spacing between the beams, Figure 10 shows a spacing reduction of between 5.94 and 
$5.58 \mathrm{~m}$ when the span lengthens. The results show that energy optimization leads to lower spacing between the beams, except for the 20-m span length. Figure 11 represents the main cross-section dimensions to clarify the impact of the span length and criteria on the design. Comparing the cost and energy criteria, it is worth noting that energy optimization takes bigger beams (greater depth and width) and smaller length of the spans between the beams and the external cantilever. This suggests that for an energy benefit it is better to reduce the transverse bending, and therefore the reinforcing steel, although this means an increase in the volume of concrete. Regarding the span length, there is a clear increment in the depth and web inclination angle.

Figure 12 illustrates the tendency to increase the concrete compressive strength with the span length. Yepes et al. (2015b) stated that the concrete strength values decrease when $\mathrm{CO}_{2}$ emissions are optimized. However, the results indicate that the energy criterion does not show a clear difference in values for the concrete strength compared to cost optimization. Only slabs in the low span lengths present smaller values for the cost objective. Beam reinforcement shows low susceptibility to the objective and high dependence on the span length (Fig. 13). An optimum value of around $2200 \mathrm{~kg}$ is obtained for a $20-\mathrm{m}$ span length, while the best energy-optimized and cost-optimized quantity for a 40-m span length is 7786 and $7500 \mathrm{~kg}$. Slab reinforcement varies between 7140 and $12809 \mathrm{~kg}$ when the objective is to reduce energy, and between 9428 and 16431 when the objective is to reduce cost (Fig. 14). Thus, as pointed previously, the results indicate that reinforcement should be reduced in the slab to decrease energy consumption. In addition, the amount of reinforcement per volume in the energyoptimization and cost-optimization is about 116-149 kg/m3 and 151-198 kg/m3. While Fomento (2000) states that the amount of reinforcement per volume in the slab can reach values between 250 and $300 \mathrm{~kg} / \mathrm{m} 3$, the optimization seeks an optimum beam spacing that provides a reinforcement reduction.

Regarding the concrete, Figures 15 and 16 show greater beam and slab volumes per square meter of deck for the energy case. These differences are, on average, $0.013 \mathrm{~m}^{3} / \mathrm{m}^{2}$ of deck and $0.025 \mathrm{~m}^{3} / \mathrm{m}^{2}$ of deck, respectively. The ratio between the unit prices of concrete and steel is greater than the ratio between the unit energy of concrete and steel. This means that an increment in the volume of concrete has more impact on the cost than on the energy. This fact explains the energy benefit of reducing the reinforcement in the slab and increasing the volume of concrete in both the slab and the beams.

Finally, the energy-optimized bridge solution with $30 \mathrm{~m}$ span length was compared with a real bridge on the 
Tarragona A-7 highway. This bridge also has a span length of $30 \mathrm{~m}$ and the same deck width as the in the optimization case. The energy savings were estimated around $24 \%$. The optimized solution decreased the length of the slab spans in the transverse direction, and consequently, the optimization achieved a reduction in the slab thickness and the slab reinforcement.

\section{Conclusions}

In this paper, the best design of precast-PC U-beam road bridges is tackled from the economic and energy points of view. The cumulative cost and embodied energy are those imputed to extract, process, manufacture, transport and place the materials. The following conclusions are drawn:

- The results of a parametric study show a parabolic relation between the span length $s$ and both the minimum cost $C$ and the minimum energy $E$, for cost optimization $\left(C=44.265 s^{2}+1034.6 s+12208\right.$ with $R^{2}=0.9995$ and $E=233.99 \mathrm{~s}^{2}+2198.1 \mathrm{~s}+99293$ with $\left.R^{2}=0.9964\right)$ and energy optimization $\left(C=48.958 s^{2}+671.05 s+17407\right.$ with $R^{2}=0.9994$ and $E=191.69 s^{2}+4333.2 s+59141$ with $\left.R^{2}=0.9996\right)$.

- In contrast to gas emission optimization, the energy criterion does not show a clear difference in values for the concrete strength compared to cost optimization.

- The ratio between the unit prices of concrete and steel is greater than the ratio between the unit energy of concrete and steel. This clarifies that the amount of reinforcement in the slab is smaller and the volumes of concrete in the beams and slab are greater for the energy optimization case.

- While the web inclination angle is commonly fixed as a parameter, the results show that it should be increased with the span length to maintain the optimum length of the slab spans in the transverse direction.

- The findings indicate that both criteria are dependent, so that, a $1 €$ reduction is equivalent to a saving of 4 $\mathrm{kWh}$. The energy reduction has an average cost impact of $3.23 €$ per square meter of deck.

- Comparing the energy-optimized solution with a $30 \mathrm{~m}$ span length and a real bridge on the Tarragona A-7 highway, it is worth noting an energy saving of around $24 \%$.

\section{Acknowledgments}

The authors acknowledge the financial support of the Spanish Ministry of Economy and Competitiveness along with FEDER funding (BRIDLIFE Project: BIA2014-56574-R). 


\section{References}

Barandica, J.M., Fernández-Sánchez, G., Berzosa, Á., Delgado, J.A., Acosta, F.J., 2013. Applying life cycle thinking to reduce greenhouse gas emissions from road projects. J. Clean. Prod. 57, 79-91. http://dx.doi.org/10.1016/j.jclepro.2013.05.036.

BEDEC, 2013. Institute of Construction Technology of Catalonia. Barcelona, Spain.

Börjesson, P., Gustavsson, L., 2000. Greenhouse gas balances in building construction: wood versus concrete from life-cycle and forest land-use perspectives. Energ. Policy 28, 575-588. http://dx.doi.org/10.1016/S03014215(00)00049-5.

Camp, C. V., Assadollahi, A., 2013. $\mathrm{CO}_{2}$ and cost optimization of reinforced concrete footings using a hybrid big bang-big crunch algorithm. Struct. Multidiscip. Optim. 48, 411-426. http://dx.doi.org/10.1007/s00158-0130897-6.

Castañón, A.M., García-Granda, S., Guerrero, A., Lorenzo, M.P., Angulo, S., 2015. Energy and environmental savings via optimisation of the production process at a Spanish cement factory. J. of Clean. Prod. 98, 47-52. http://dx.doi.org/10.1016/j.jclepro.2014.03.028.

De Medeiros, G.F., Kripka, M., 2014. Optimization of reinforced concrete columns according to different environmental impact assessment parameters. Eng. Struct. 59, 185-194. http://dx.doi.org/10.1016/j.engstruct.2013.10.045.

Fomento, M., 2000. New overpasses: general concepts. Ministerio de Fomento. Madrid, Spain.

Fomento, M., 2008. EHE-08: Code on structural concrete. Ministerio de Fomento. Madrid, Spain.

Fomento, M., 1998. IAP-98: Code on the actions for the design of road bridges. Madrid, Spain.

Foraboschi, P., Mercanzin, M., Trabucco, D., 2014. Sustainable structural design of tall buildings based on embodied energy. Energy Build. 68, 254-269. http://dx.doi.org/10.1016/j.enbuild.2013.09.003

García-Segura, T., Yepes, V., Alcalá, J., 2014a. Life cycle greenhouse gas emissions of blended cement concrete including carbonation and durability. Int. J. Life Cycle Assess. 19(1), 3-12. http://dx.doi.org/10.1007/s11367-013-0614-0.

García-Segura, T., Yepes, V., Alcalá, J., Pérez-López, E., 2015. Hybrid harmony search for sustainable design of post-tensioned concrete box-girder pedestrian bridges. Eng. Struct. 92, 112-122. http://dx.doi.org/10.1016/j.engstruct.2015.03.015.

García-Segura, T., Yepes, V., Martí, J.V., Alcalá, J., 2014b. Optimization of concrete I-beams using a new hybrid glowworm swarm algorithm. Lat. Am. J. Solids Struct. 11(7), 1190-1205. http://dx.doi.org/10.1590/S1679-78252014000700007.

González, M.J., García Navarro, J., 2006. Assessment of the decrease of $\mathrm{CO}_{2}$ emissions in the construction field through the selection of materials: Practical case study of three houses of low environmental impact. Build. Environ. 41(7), 902-909. http://dx.doi.org/10.1016/j.buildenv.2005.04.006.

Holland, J., 1975. Adaptation in Natural and Artificial Systems, University of Michigan Press, Ann Arbor, USA.

Kirkpatrick, S., Gelatt, C.D., Vecchi, M.P., 1983. Optimization by simulated annealing. Science 220(4598), 671-680. http://dx.doi.org/10.1126/science.220.4598.671.

Li, X.-G., Wei, X., 2008. An Improved Genetic Algorithm-Simulated Annealing Hybrid Algorithm for the Optimization of Multiple Reservoirs. Water Resour. Manag. 22(8), 1031-1049. http://dx.doi.org/10.1007/s11269-007-9209-5.

Lippiatt, B.C., 1999. Selecting Cost-Effective Green Building Products: BEES Approach. J. Constr. Eng. Manag. 125(6), 448-455. http://dx.doi.org/10.1061/(ASCE)0733-9364(1999)125:6(448), 448-455.

Martí, J. V., Gonzalez-Vidosa, F., Yepes, V., Alcalá, J., 2013. Design of prestressed concrete precast road bridges with hybrid simulated annealing. Eng. Struct. 48, 342-352. http://dx.doi.org/10.1016/j.engstruct.2012.09.014. 
Martí, J.V.; Yepes, V.; González-Vidosa, F., 2015. Memetic algorithm approach to designing of precastprestressed concrete road bridges with steel fiber-reinforcement. J. Struct. Eng. 141(2), 04014114. http://dx.doi.org/10.1061/(ASCE)ST.1943-541X.0001058, 04014114.

Miller, D., Doh, J.-H., Mulvey, M., 2015. Concrete slab comparison and embodied energy optimisation for alternate design and construction techniques. Constr. Build. Mater. 80, 329-338. http://dx.doi.org/10.1016/j.conbuildmat.2015.01.071.

Park, H., Kwon, B., Shin, Y., Kim, Y., Hong, T., Choi, S., 2013. Cost and $\mathrm{CO}_{2}$ Emission Optimization of Steel Reinforced Concrete Columns in High-Rise Buildings. Energies 6(11), 5609-5624. http://dx.doi.org/10.3390/en6115609.

Pellicer, E., Sierra, L.A., Yepes, V., 2016. Appraisal of infrastructure sustainability by graduate students using an active-learning method. J. of Clean. Prod. (in press). http://dx.doi.org/10.1016/j.jclepro.2015.11.010.

Quaglia, C.P., Yu, N., Thrall, A.P., Paolucci, S., 2014. Balancing energy efficiency and structural performance through multi-objective shape optimization: Case study of a rapidly deployable origami-inspired shelter. Energy Build. 82, 733-745. http://dx.doi.org/10.1016/j.enbuild.2014.07.063.

Sattary, S., Thorpe, D., 2012. Optimizing embodied energy of building construction through bioclimatic principles. Proc. 28th Annu. Conf. Assoc. Res. Constr. Manag. (ARCOM 2012).

Senaratne, S., Gerace, D., Mirza, O., Tam, V.W.Y., 2016. The costs and benefits of combining recycled aggregate with steel fibres as a sustainable, structural material. J. of Clean. Prod. 112, 2318-2327. http://dx.doi.org/10.1016/j.jclepro.2015.10.041.

Soke, A., Bingul, Z., 2006. Hybrid genetic algorithm and simulated annealing for two-dimensional nonguillotine rectangular packing problems. Eng. Appl. Artif. Intell. 19(5), 557-567. http://dx.doi.org/10.1016/j.engappai.2005.12.003.

Tae, S., Baek, C., Shin, S., 2011. Life cycle $\mathrm{CO}_{2}$ evaluation on reinforced concrete structures with high-strength concrete. Environ. Impact Assess. Rev. 31(3), 253-260. http://dx.doi.org/10.1016/j.eiar.2010.07.002.

Tosic, N., Marinkovic, S., Dasic, T., Stanic, M., 2015. Multicriteria optimization of natural and recycled aggregate concrete for structural use. J. of Clean. Prod. 87, 766-776. http://dx.doi.org/10.1016/j.jclepro.2014.10.070.

Wang, E., Shen, Z., 2013. A hybrid Data Quality Indicator and statistical method for improving uncertainty analysis in LCA of complex system - application to the whole-building embodied energy analysis. J. Clean. Prod. 43, 166-173. http://dx.doi.org/10.1016/j.jclepro.2012.12.010.

Wang, T., Lee, I.-S., Kendall, A., Harvey, J., Lee, E.-B., Kim, C., 2012. Life cycle energy consumption and GHG emission from pavement rehabilitation with different rolling resistance. J. Clean. Prod. 33, 86-96. http://dx.doi.org/10.1016/j.jclepro.2012.05.001.

World Business Council for Sustainable Development (WBCSD), 2009. Cement Industry Energy and $\mathrm{CO}_{2}$ Performance: Getting the Numbers Right

http://www.wbcsd.org/Pages/EDocument/EDocumentDetails.aspx?ID=11095

World Energy Counc, 1995. Efficient Use of Energy Utilizing High Technology: An Assessment of Energy Use in Industry and Buildings.

Yeo, D., Gabbai, R.D., 2011. Sustainable design of reinforced concrete structures through embodied energy optimization. Energy Build. 43(8), 2028-2033. http://dx.doi.org/10.1016/j.enbuild.2011.04.014.

Yepes, V., García-Segura, T., Moreno-Jiménez, J.M., 2015a. A cognitive approach for the multi-objective optimization of RC structural problems. Arch. Civ. Mech. Eng. 15(4), 1024-1036. http://dx.doi.org/10.1016/j.acme.2015.05.001.

Yepes, V., Gonzalez-Vidosa, F., Alcala, J., Villalba, P., 2012. $\mathrm{CO}_{2}$-Optimization Design of Reinforced Concrete Retaining Walls Based on a VNS-Threshold Acceptance Strategy. J. Comput. Civ. Eng. 26(3), 378386. http://dx.doi.org/10.1061/(ASCE)CP.1943-5487.0000140. 
Yepes, V., Martí, J. V., García-Segura, T., 2015b. Cost and $\mathrm{CO}_{2}$ emission optimization of precast-prestressed concrete U-beam road bridges by a hybrid glowworm swarm algorithm. Autom. Constr. 49, $123-134$. http://dx.doi.org/10.1016/j.autcon.2014.10.013.

Zhong, Y., Wu, P., 2015. Economic sustainability, environmental sustainability and constructability indicators related to concrete- and steel-projects. J. of Clean. Prod. 108, 748-756. http://dx.doi.org/10.1016/j.jclepro.2015.05.095.

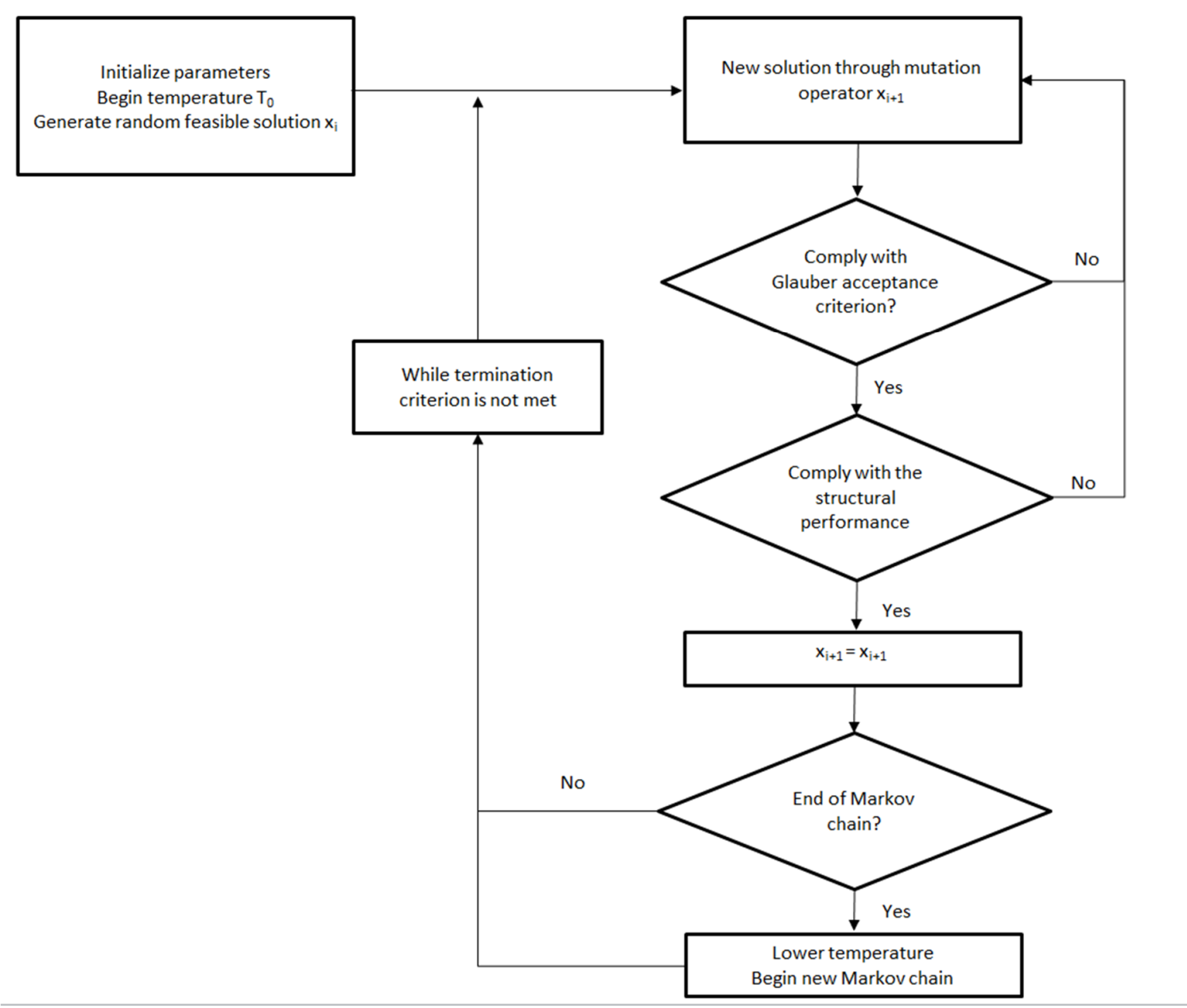

Fig. 1. Flowchart of the optimization technique 




Fig. 2. General cross section of PC precast road bridge 


\section{Span/2}


$b_{1}$

Fig. 3. Main beam and slab variables

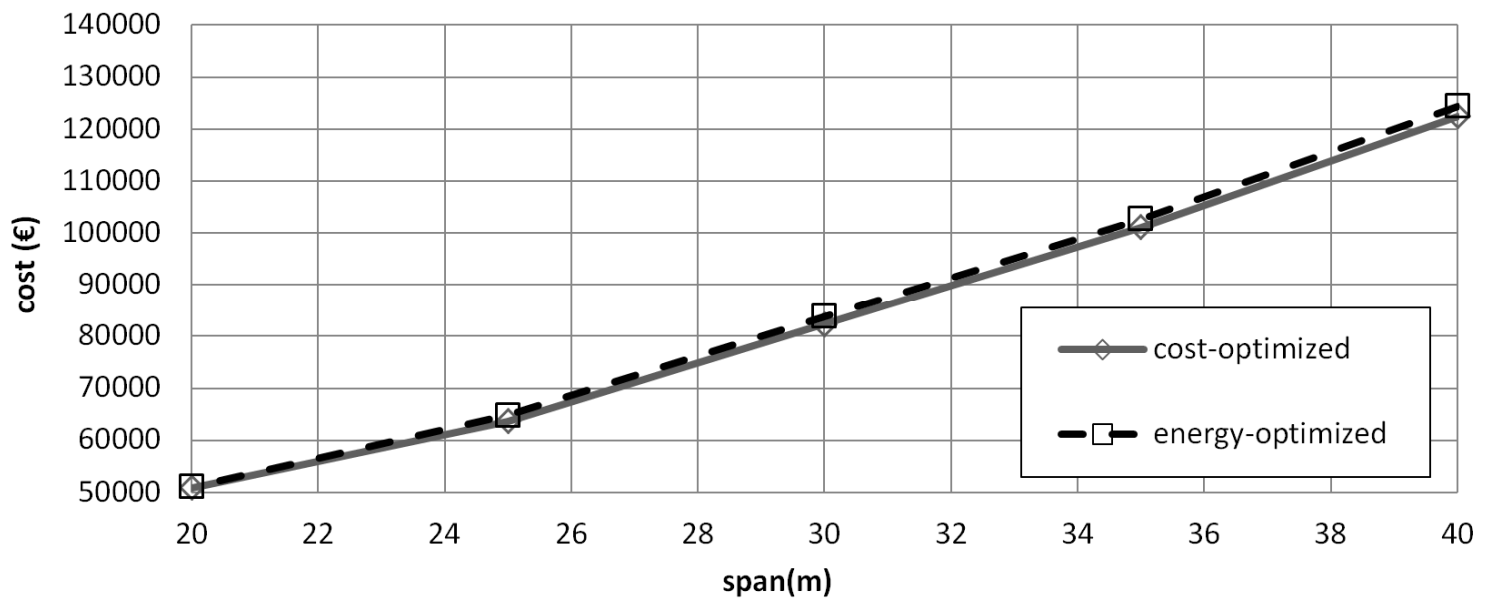

Fig. 4. Mean cost according to the span length 


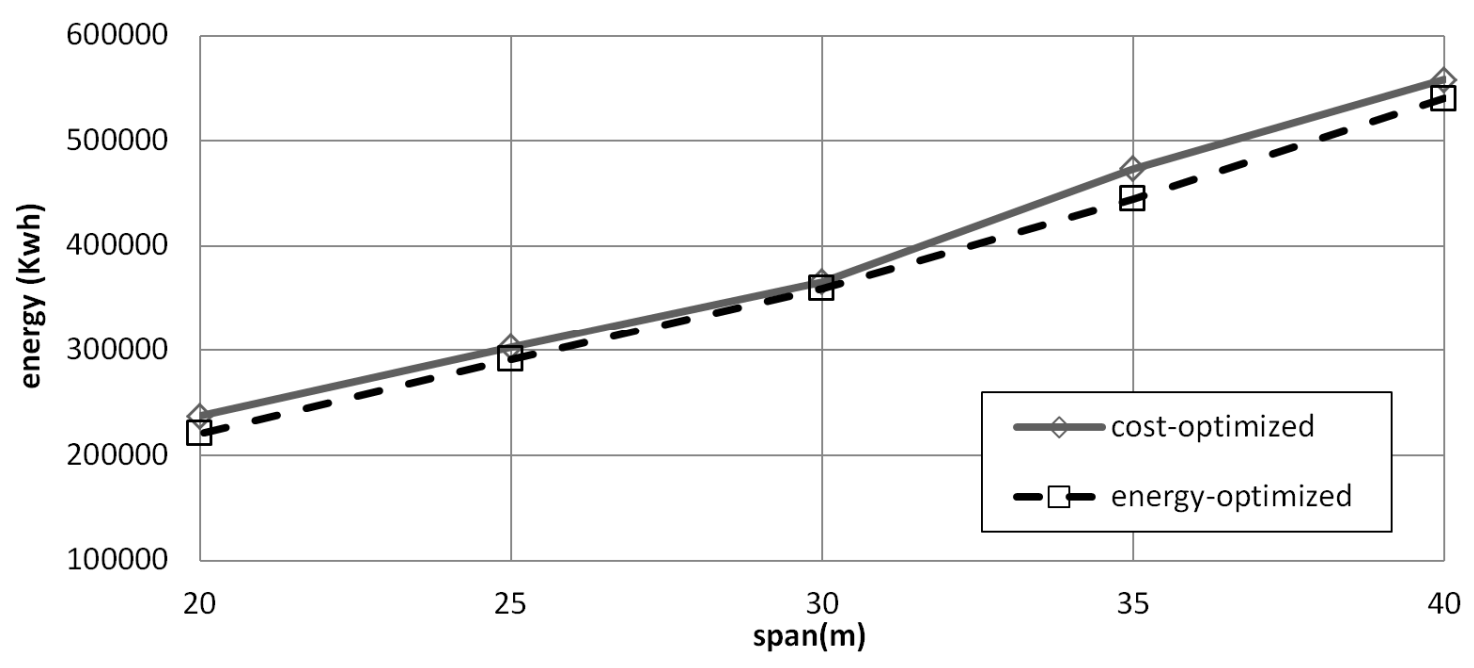

Fig. 5. Mean energy according to the span length

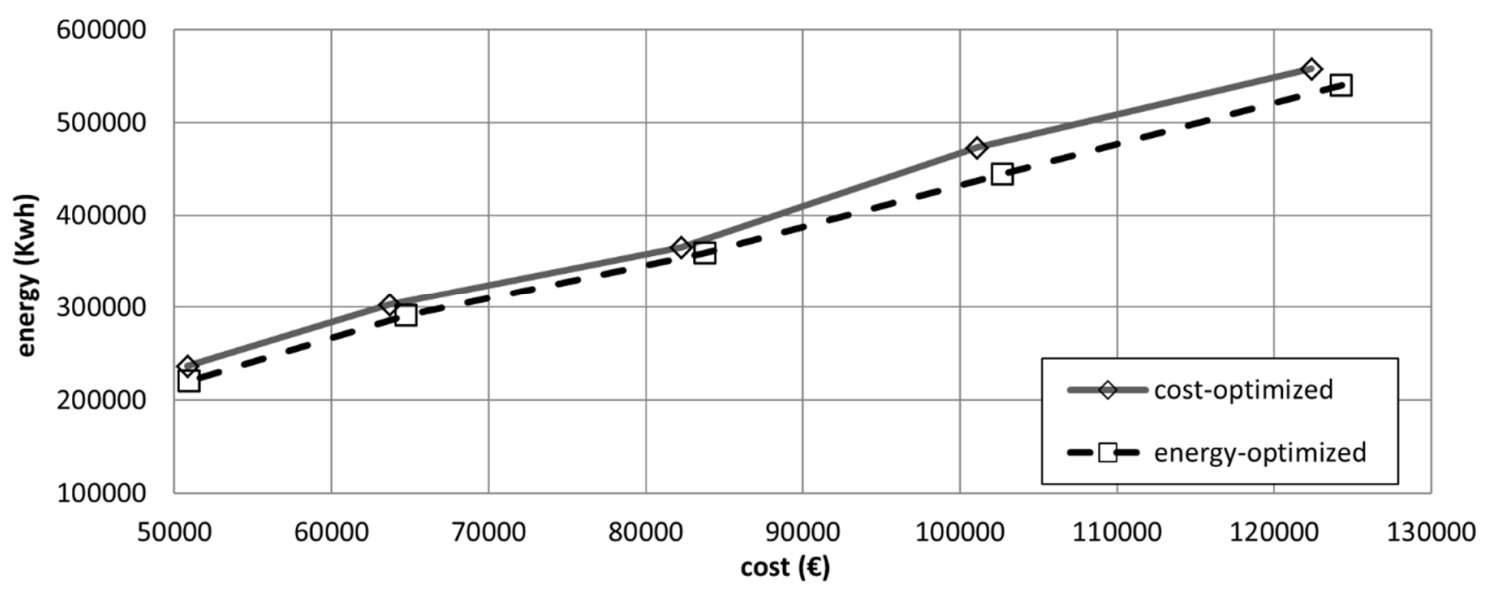

Fig. 6. Relationship between energy and cost 




Fig. 7. Mean beam depth according to the span length



Fig. 8. Mean web inclination angle according to the span length 


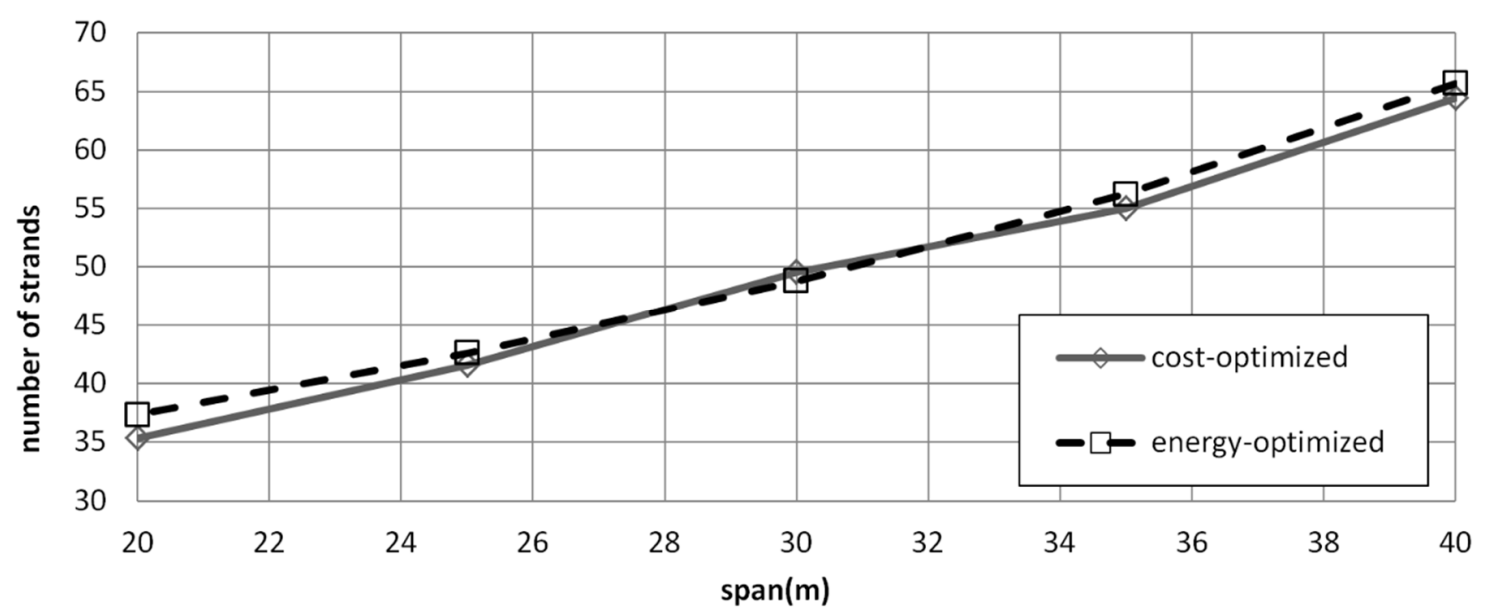

Fig. 9. Mean number of strands according to the span length

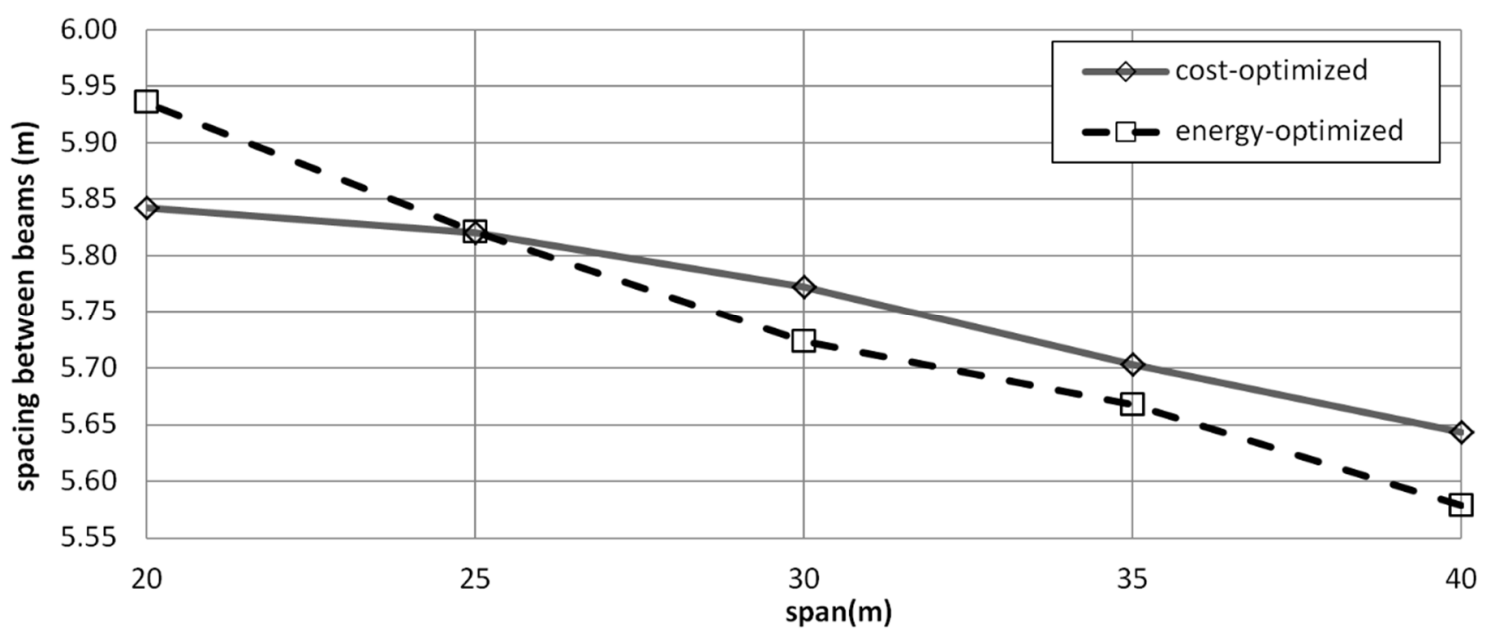

Fig. 10. Mean spacing between beams according to the span length 


\section{Cost objective}

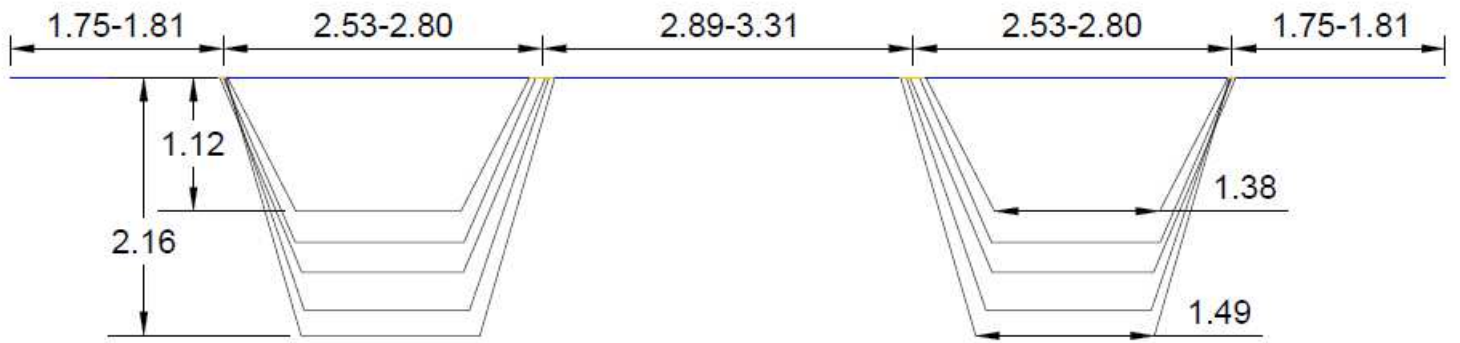

\section{Energy objective}

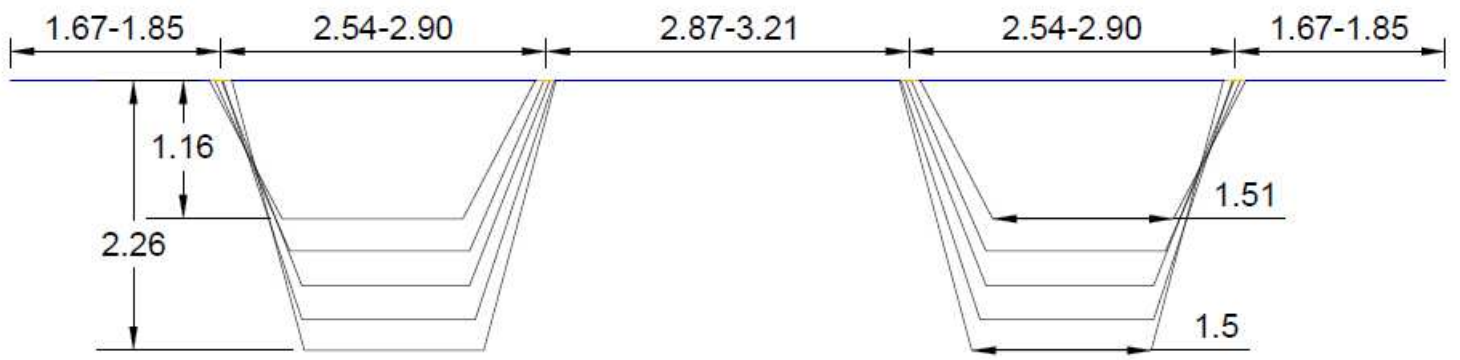

Fig. 11. Mean cross-section dimensions according to the span length and criteria

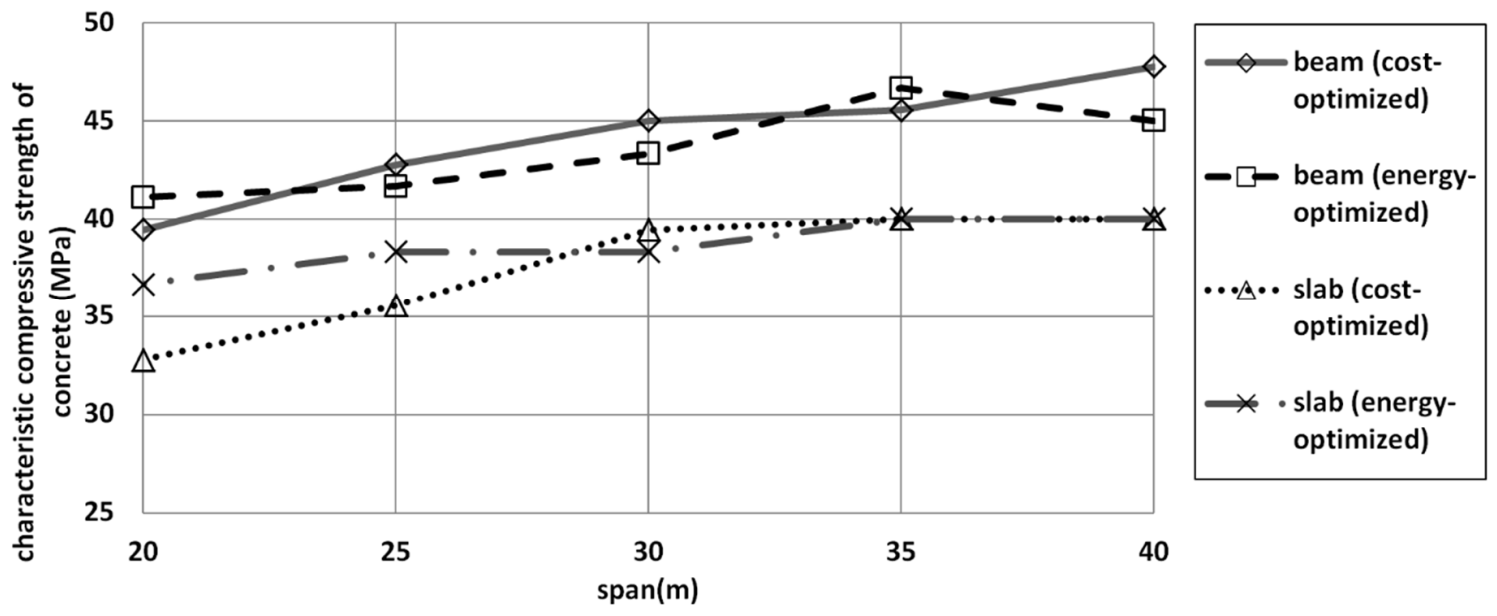

Fig. 12. Mean concrete strength between beams according to the span length 


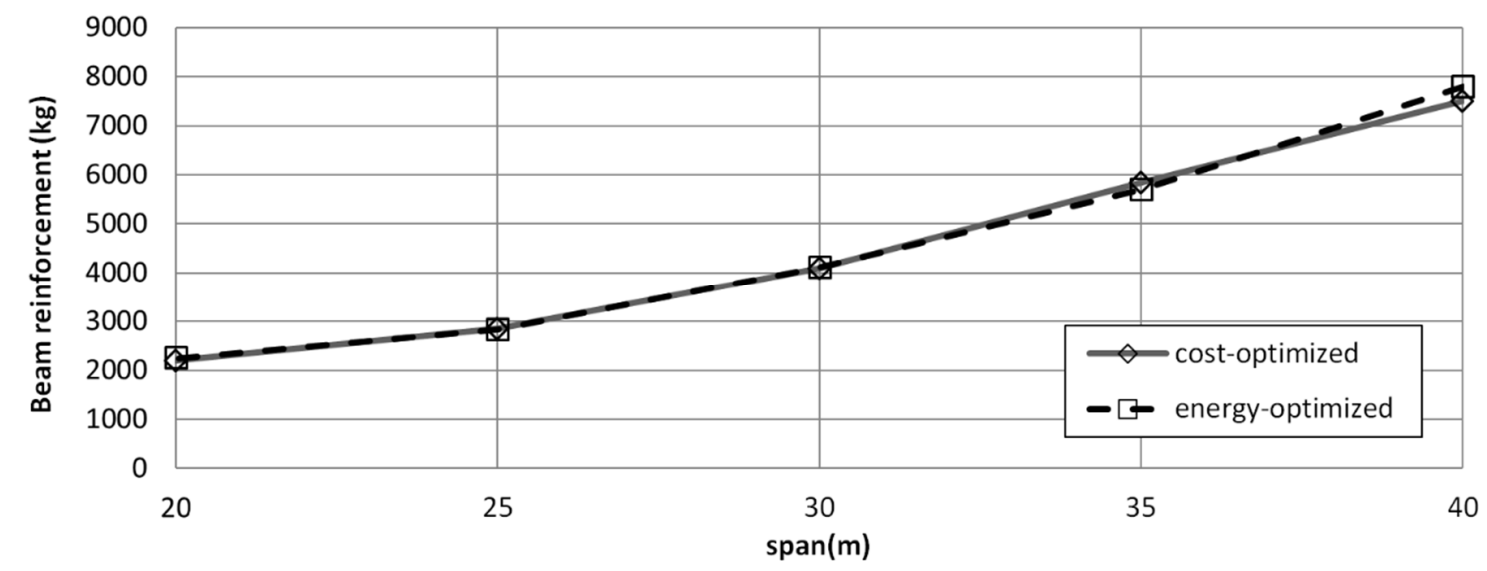

Fig. 13. Mean beam reinforcement according to the span length

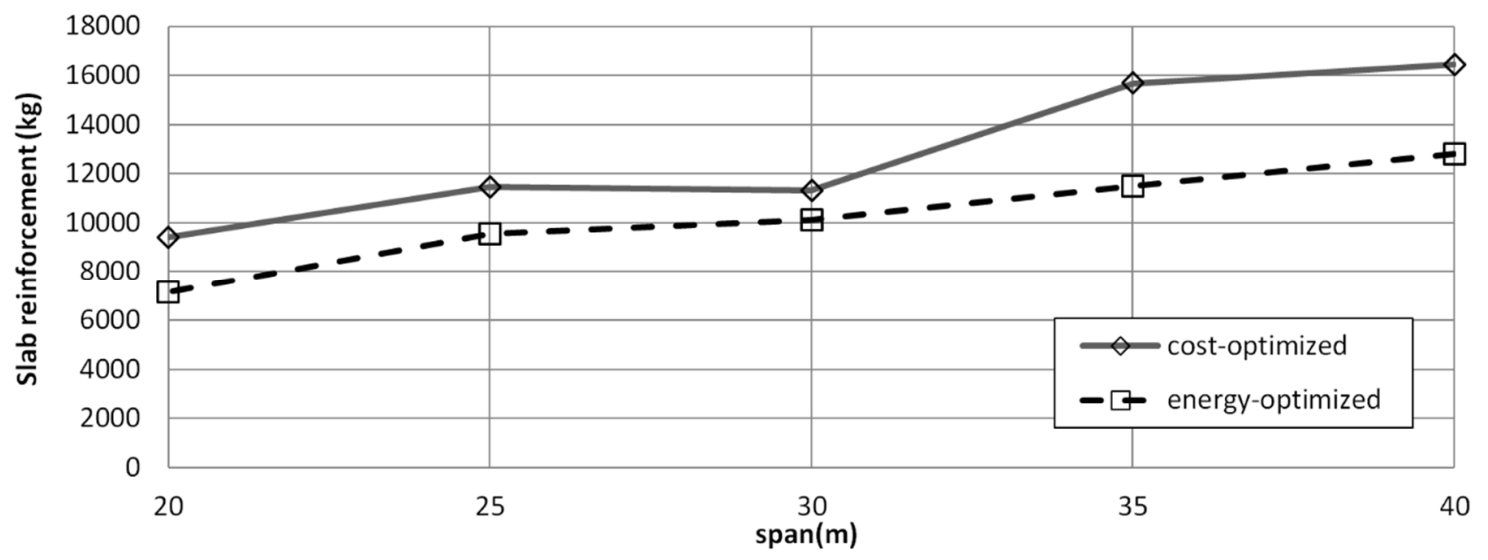

Fig. 14. Mean slab reinforcement according to the span length

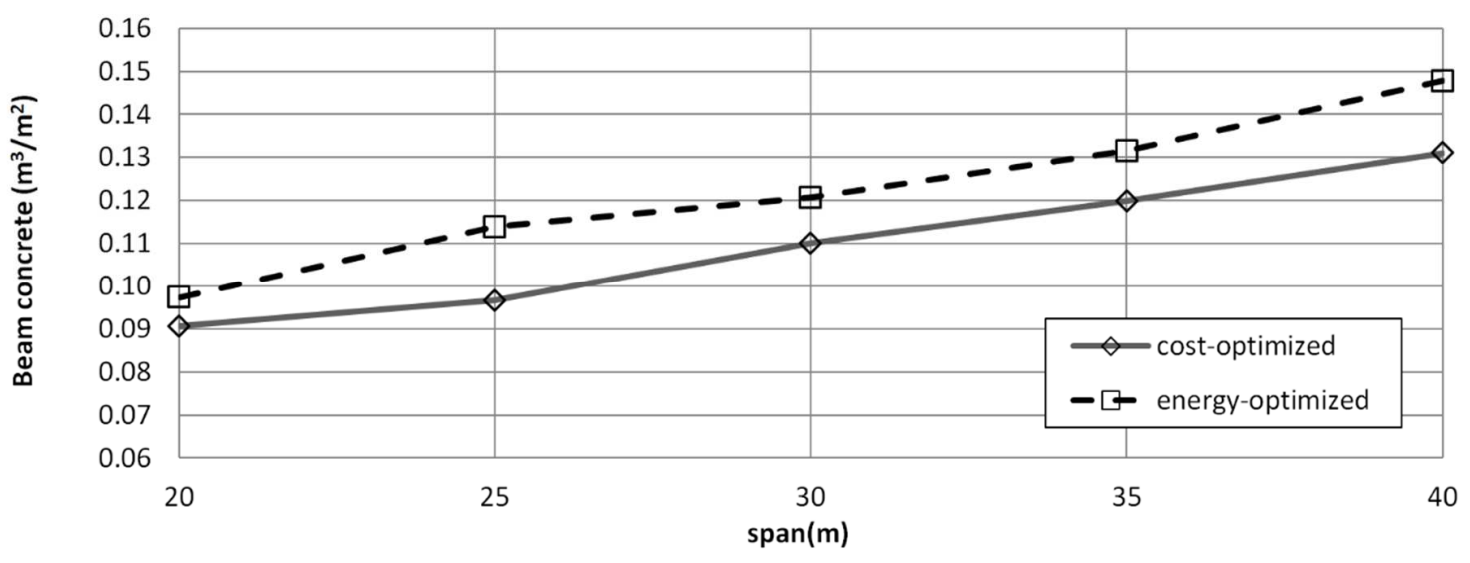

Fig. 15. Mean beam concrete according to the span length 


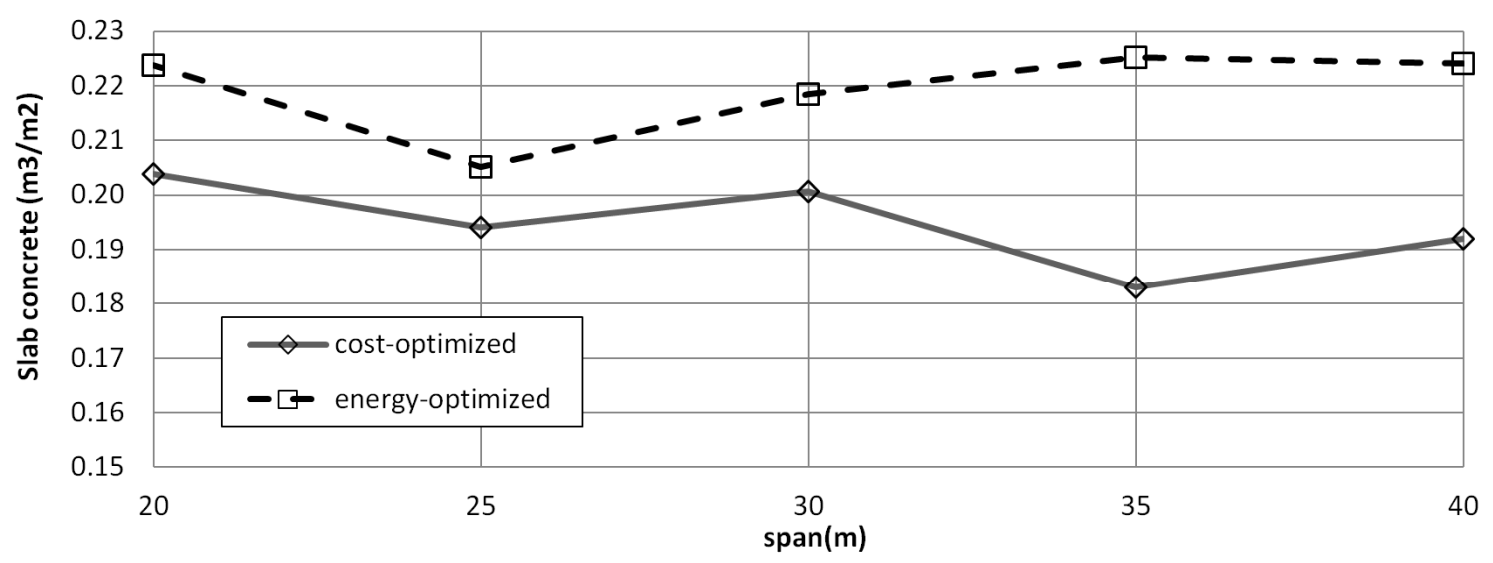

Fig. 16. Mean slab concrete according to the span length

Table 1. Unit prices and energy

\begin{tabular}{cccc}
\hline Unit & Description & Cost (€) & $\begin{array}{c}\text { Energy } \\
(\mathbf{k W h})\end{array}$ \\
\hline $\mathrm{kg}$ & steel in beam (B-500-S) & 1.53 & 10.44 \\
$\mathrm{~kg}$ & steel in slab (B-500-S) & 1.18 & 10.47 \\
$\mathrm{~kg}$ & active steel (Y1860-S7) & 2.32 & 12.99 \\
$\mathrm{~m}^{2}$ & beam formwork & 21.21 & 51.99 \\
$\mathrm{~m}^{2}$ & slab formwork & 32.00 & 124.67 \\
$\mathrm{~m}^{3}$ & concrete in slab HA-25 & 94.00 & 412.99 \\
$\mathrm{~m}^{3}$ & concrete in slab HA-30 & 102.72 & 438.84 \\
$\mathrm{~m}^{3}$ & concrete in slab HA-35 & 109.85 & 464.97 \\
$\mathrm{~m}^{3}$ & concrete in slab HA-40 & 117.27 & 495.11 \\
$\mathrm{~m}^{3}$ & concrete in beam HP-35 & 138.74 & 477.83 \\
$\mathrm{~m}^{3}$ & concrete in beam HP-40 & 144.96 & 501.72 \\
$\mathrm{~m}^{3}$ & concrete in beam HP-45 & 155.70 & 514.49 \\
$\mathrm{~m}^{3}$ & concrete in beam HP-50 & 167.46 & 525.50 \\
\hline
\end{tabular}


Table 2. Energy and prices from beam transport and placement according to the beam length

\begin{tabular}{cccc}
\hline $\begin{array}{c}\text { Maximum beam } \\
\text { length }(\mathbf{m})\end{array}$ & $\begin{array}{c}\text { Transport energy } \\
(\mathbf{k W h} / \mathbf{t})\end{array}$ & $\begin{array}{c}\text { Placement energy } \\
(\mathbf{k W h} / \mathbf{m})\end{array}$ & $\begin{array}{c}\text { Placement cost } \\
(\mathfrak{\epsilon})\end{array}$ \\
\hline 20 & 81.23 & 41.93 & 3103 \\
25 & 85.21 & 53.42 & 3210 \\
30 & 104.48 & 64.92 & 5457 \\
35 & 101.44 & 69.30 & 5564 \\
40 & 98.40 & 73.71 & 6634 \\
\hline
\end{tabular}

Table 3. Prices for beam transport according to the beam weight

\begin{tabular}{cc}
\hline $\begin{array}{c}\text { Maximum beam weight } \\
(\mathbf{k N})\end{array}$ & $\begin{array}{c}\text { Transport cost } \\
(\boldsymbol{€})\end{array}$ \\
\hline 550 & 1043 \\
660 & 1364 \\
800 & 1765 \\
1000 & 1952. \\
2000 & 3022 \\
4000 & 4092 \\
\hline
\end{tabular}


Table 4. Parameters for the case study

\begin{tabular}{ll}
\hline Width of the bridge $(w)$ & $12.00 \mathrm{~m}$ \\
Inclination of top flange tablet & $1 / 3$ \\
Top flange division & 3 \\
Inclination of bottom flange tablet & $1 / 3$ \\
Bottom flange division & 4 \\
Minimum beam slenderness (span length over beam depth) & $L / 17$ \\
Distance from bearing center to beam face & $0.47 \mathrm{~m}$ \\
With of concrete bridge barrier $(b)$ & $2 \times 0.50 \mathrm{~m}$ \\
Thickness of the wearing surface & $0.09 \mathrm{~m}$ \\
Bridge barrier load & $2 \times 5.0 \mathrm{kN} / \mathrm{m}$ \\
One way transport distance & $50 \mathrm{~km}$ \\
Active prestressing steel crops & $25 \%$ \\
Reinforcing steel strength & $500 \mathrm{~N} / \mathrm{mm}{ }^{2}$ \\
Prestressing steel strength & $1700 \mathrm{~N} / \mathrm{mm}^{2}$ \\
Strand diameter & $0.6 ”$ \\
Beam surface reinforcement & $8 \mathrm{~mm}$ \\
Strand sheaths levels & $2 \mathrm{and} 3$ \\
Stirrups slenderness (length/diameter) & 200 \\
Structural codes & $\mathrm{EHE}-08 / \mathrm{IAP}-98$ \\
External ambient exposure & $\mathrm{EHE}-08)$ \\
\hline
\end{tabular}

Table 5.Mean values of energy (a) and cost (b) optimized solutions

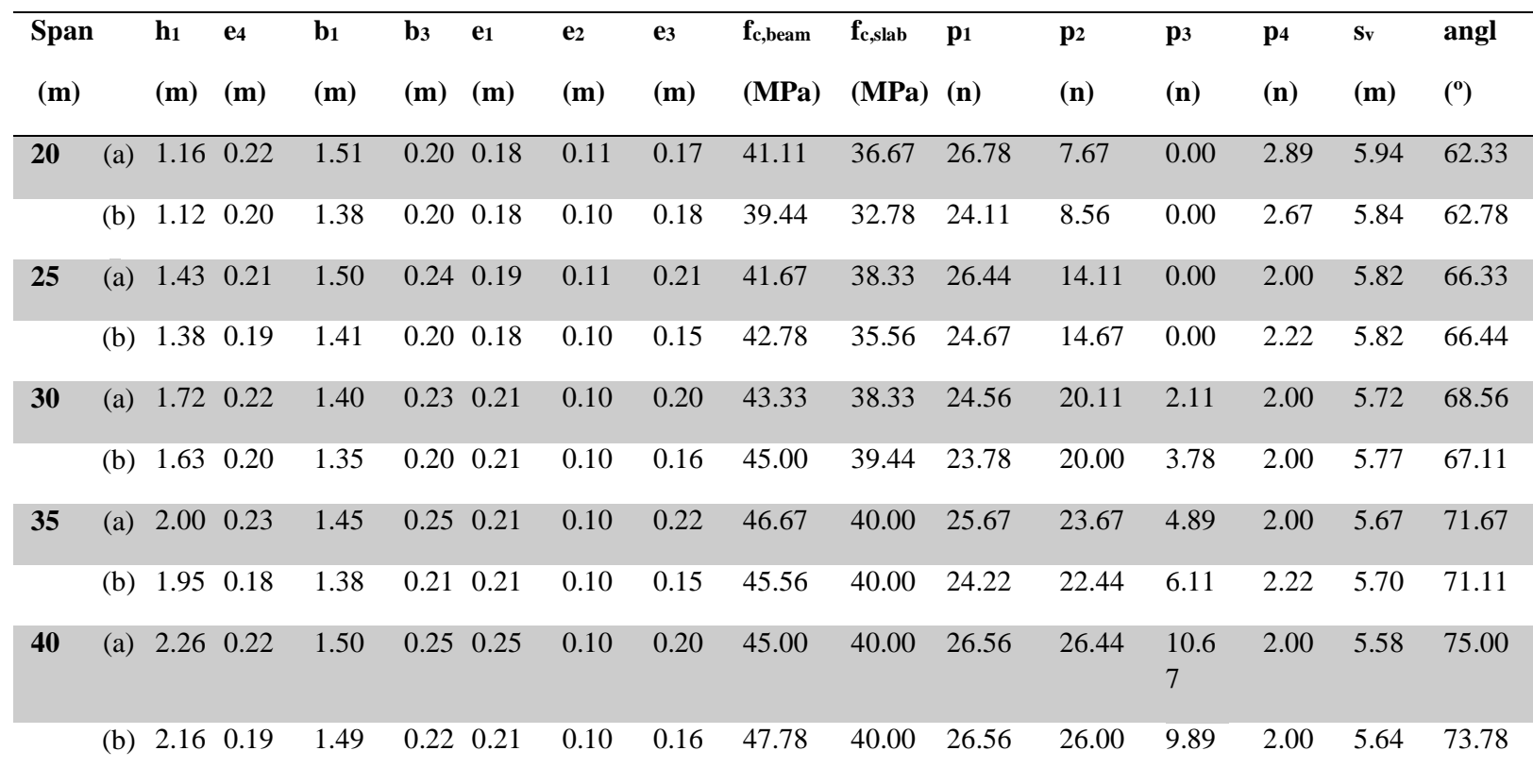


